\title{
Global developmental delay-visual anomalies-progressive cerebellar atrophy-truncal hypotonia syndrome
}

INSERM

\section{Source}

INSERM. (1999). Orphanet: an online rare disease and orphan drug data base. Global developmental delay-visual anomalies-progressive cerebellar atrophy-truncal hypotonia syndrome. ORPHA:480898

Global developmental delay-visual anomalies-progressive cerebellar atrophy-truncal hypotonia syndrome is a rare, genetic, neurological disorder characterized by mild to severe developmental delay and speech impairment, truncal hypotonia, abnormalities of vision (including cortical visual impairment and abnormal visual-evoked potentials), progressive brain atrophy mainly affecting the cerebellum, and shortened or atrophic corpus callosum. Other clinical findings may include increased muscle tone in the extremities, dystonic posturing, hyporeflexia, scoliosis, postnatal microcephaly and variable facial dysmorphism (e.g. deep-set eyes, ging ival hyperplasia, short philtrum and retrognathia). 